\title{
Cultural Factors Influencing the Utilization or Production of Acetate by Butyrivibrio fibrisolvens
}

\author{
By M. J. LATHAM AND N. J. LEGAKIS \\ National Institute for Research in Dairying, Shinfield, Reading RG2 9AT, Berkshire
}

(Received Io October 1975)

S UMMARY

Utilization of acetate by four strains of Butyrivibrio fibrisolvens was influenced by the composition of their growth medium. Growth-limiting glucose concentrations, low availability of $\mathrm{CO}_{2}$ and the presence of sodium lactate all stimulated acetate uptake by three strains. The type strain, $\mathrm{D}_{1}$, utilized acetate if the concentration of acetate added to the medium was at least $15 \mu \mathrm{mol} \mathrm{ml}^{-1}$. In batch culture, all strains produced acetate before entering a phase of acetate uptake. Continuous-culture studies with one strain showed that acetate uptake was dependent upon growth rate. The amount of n-butyrate produced in batch or continuous culture was closely linked to the amount of acetate taken up.

\section{INTRODUCTION}

Bacteria belonging to the genus Butyrivibrio produce large amounts of n-butyric acid by fermentation of carbohydrates (Bryant \& Small, 1956). They generally occur as a major part of the microflora in the rumen of animals given high roughage rations and having a rumen fermentation characterized by a large molar proportion of acetic acid (Shane, Gouws \& Kistner, 1969; Latham, Sutton \& Sharpe, 1974). Division into species has proved difficult and only one species, Butyrivibrio fibrisolvens, is recognized (Bergey's Manual of Determinative Bacteriology, 1974). Shane et al. (1969) proposed that butyrivibrios be divided into two groups according to the relative proportions of their fermentation products. Group I strains utilize acetic acid and produce large amounts of lactic and small amounts of formic acids; Group 2 strains produce acetic acid and relatively small amounts of lactic and large amounts of formic acids. Most strains isolated belong to Group I.

Experiments involving infusion of ${ }^{14} \mathrm{C}$-labelled volatile fatty acids into the rumen have demonstrated that considerable interconversion of acetate and n-butyrate carbon occurs in vivo (Leng, 1970) and recently Emmanuel, Milligan \& Turner (1974) found extensive incorporation of ${ }^{14} \mathrm{C}$ from $\left[\mathrm{I}^{-14} \mathrm{C}\right]$ acetate into rumen microbial protein, nucleic acid and lipids. It is possible that Group I butyrivibrios are involved in the metabolism of acetate within the rumen. The fermentation products of butyrivibrios are influenced by changes in $\mathrm{pH}$ and in the proportion of rumen fluid in the growth medium (Lee \& Moore, 1959). We describe here cultural factors affecting acetate uptake or production in batch and continuous culture by strains of B. fibrisolvens which resemble Shane's Group I butyrivibrios. 


\section{METHODS}

Organisms. The type strain of $B$. fibrisolvens, $\mathrm{D}_{1}$, and strain 49 were provided by Dr M.P. Bryant, and strain KIO (KIO-02-04-6B) was provided by Dr N. O. van Gylswyk. Strains NOR37 and IL63I were previously isolated in this laboratory (Sharpe \& Reiter, I972).

Media. The Hungate technique of anaerobic culture (Bryant \& Robinson, 1961) was used throughout and all incubations were at $39^{\circ} \mathrm{C}$ for $48 \mathrm{~h}$ unless stated otherwise. Cultures were maintained on medium Io agar slants (Caldwell \& Bryant, 1966). A medium containing rumen fluid and $0.5 \%$ (w/v) cellobiose (Kistner, 1960; Shane et al., 1969) was used to determine to which of Shane's two fermentation groups the strains belonged.

The basal synthetic (BS) medium used for all other growth studies contained (per $100 \mathrm{ml}$ ): $0.2 \mathrm{~g}$ trypticase (BBL);0.4 $\mathrm{g}$ yeast extract (Difco) $77.5 \mathrm{ml}$ mineral solution $\mathrm{I} ; 7.5 \mathrm{ml}$ mineral solution II; $0 . \mathrm{I} \mathrm{ml} \mathrm{of} 0 . \mathrm{I} \%(\mathrm{w} / \mathrm{v})$ resazurin solution. The compositions of the mineral solutions were: solution I, $\mathrm{K}_{2} \mathrm{HPO}_{4}\left(0.6 \%\right.$, w/v); solution II, $\mathrm{KH}_{2} \mathrm{PO}_{4}(0.6 \%$, w/v); $\mathrm{NaCl}$ $(\mathrm{I} \cdot 2 \%, \mathrm{w} / \mathrm{v}) ;\left(\mathrm{NH}_{4}\right)_{2} \mathrm{SO}_{4}\left(\mathrm{I} \cdot 2 \%\right.$ w/v); $\mathrm{MgSO}_{4} \cdot 7 \mathrm{H}_{2} \mathrm{O}(0.25 \%, \mathrm{w} / \mathrm{v}) ; \mathrm{CaCl}_{2}$ anhydrous $(0.12 \%, w / v)$. Medium ingredients were made up to the appropriate volume with water and the $\mathrm{pH}$ was adjusted to 6.8 with $\mathrm{I} \cdot 0 \mathrm{M}-\mathrm{NaOH}$ before autoclaving. Sterile $8 \cdot 0 \%(\mathrm{w} / \mathrm{v}) \mathrm{Na}_{2} \mathrm{CO}_{3}$ $(5.0 \mathrm{ml})$ and sterile $2.5 \%(\mathrm{w} / \mathrm{v})$ cysteine- $\mathrm{HCl}(2.0 \mathrm{ml})$ were added to the medium after autoclaving. None of the strains grew in the basal medium alone. Volatile fatty acids (VFA), acetic, propionic and n-butyric acids, were added individually, or as a mixture together with isobutyric, isovaleric and n-valeric acids, before adjustment of $\mathrm{pH}$, to give final concentrations as used in medium 10, except where otherwise indicated. In the absence of added acetic acid, the medium contained 3 to $5 \mu \mathrm{mol}$ acetate $/ \mathrm{ml}$ from an impurity in the trypticase. Glucose, cellobiose and maltose were added as separate sterile solutions after autoclaving. The BS medium with added acetic acid (medium BSA) was used for the batch and continuous culture studies with glucose as the sole energy source. For these studies, the BSA medium was autoclaved and gassed with oxygen-free $\mathrm{CO}_{2}$ on removal from the autoclave. Glucose, sodium carbonate and cysteine- $\mathrm{HCl}$ solutions were added and the medium allowed to equilibrate to $39{ }^{\circ} \mathrm{C}$, with continuous gassing with oxygen-free $\mathrm{CO}_{2}$, before inoculation. BSA medium with a low availability of $\mathrm{CO}_{2}$ was prepared using $0.2 \mathrm{M}$-phosphate-citrate buffer, $\mathrm{pH} 6.8$, reducing the final concentration of sodium carbonate to $0.04 \%(\mathrm{w} / \mathrm{v})$, and using I00 \% oxygen-free $\mathrm{N}_{2}$ as the headspace gas.

Apparatus. Batch-culture studies were made using 31 Erlenmeyer flasks closed with rubber stoppers fitted with ports for gas inlet and outlet, medium sampling and inoculation. Continuous-culture studies were made using a New Brunswick $\mathrm{C}_{3}$ o chemostat (New Brunswick Scientific Co., New Brunswick, New Jersey, U.S.A.) modified as follows: all silicone rubber tubing was replaced with butyl rubber tubing except for the medium delivery line where it passed around the pump; the medium reservoir, the headspace of the growth vessel and the spent medium collection vessel were gassed with independently controlled streams of oxygenfree $\mathrm{CO}_{2}$; traps chilled in ice were incorporated in the effluent gas lines to remove moisture which would otherwise have condensed in the filters; gas filters were made from I $50 \times 25 \mathrm{~mm}$ glass tubing packed with glass wool. Sampling was achieved by temporarily diverting the outflow from the growth vessel to a side arm fitted with a tap.

Analysis. Optical densities of broth cultures were determined at $660 \mathrm{~nm}$ using a Cecil CE272 spectrophotometer (Cecil lnstruments, Cambridge).

Acetic, propionic and n-butyric acids were determined by gas-liquid chromatography using a Perkin Elmer 88I chromatograph fitted with a flame ionization detector (Perkin Elmer, Beaconsfield, Buckinghamshire). Cell-free culture supernatant ( $\mathrm{I} \mathrm{ml}$ ) was acidified 
with $0.6 \mathrm{M}$-orthophosphoric acid $(0.05 \mathrm{ml})$ and $\mathrm{n}$-pentanol [0.1 $\mathrm{ml}$ of a $0.25 \%(\mathrm{v} / \mathrm{v})$ solution] was added as an internal standard. The components, in $2 \mu \mathrm{l}$ subsamples, were separated on a $6 \mathrm{ft} \times \frac{1}{8}$ in stainless-steel column packed with Chromosorb 80- 100 , polyethylene glycol 400 and orthophosphoric acid ( $18: 2: 0 \cdot 1$, by weight) at $115{ }^{\circ} \mathrm{C}$ with nitrogen $\left(35 \mathrm{ml} \mathrm{min}^{-1}\right)$ as carrier gas.

Formic acid (Rabinowitz \& Pricer, I965), L(+)-lactic acid (Garvie, I967), ethanol (Bonnichsen, 1965) and glucose (Sigma glucose oxidase kit) were determined enzymically. Total lactic acid was determined by the colorimetric method of Barker \& Summerson (194I).

Hydrogen was determined from I ml of headspace gas by gas chromatography (Pye 104 chromatograph, katharometer detector; Pye Unicam, Cambridge) using a $5 \mathrm{ft} \times \frac{1}{4}$ in glass column packed with silica gel (100 mesh) and using nitrogen $(50 \mathrm{ml} \mathrm{min}-1$ ) as the carrier gas.

\section{RESULTS}

\section{Grouping of strains using a rumen fluid medium}

Strains NOR37, IL63I and 49 utilized acetic acid and produced large amounts of lactic acid and small amounts of formic acid when grown in the rumen fluid cellobiose medium (Table 1). On this basis they were classified as Group I organisms. Strain KIO, previously characterized as a typical Group 2 organism (N. O. van Gylswyk, personal communication), was included for comparison. This strain produced acetic acid and more formic acid than the other three strains but considerably less lactic acid. The type strain, $B$. fibrisolvens $\mathrm{D}_{1}$, could not be classified on the basis of its fermentation products in this medium since although lactic acid was a major product, acetate was produced and not utilized. Apart from strain IL63I, all strains produced substantial amounts of hydrogen.

\section{Acetate uptake or production using synthetic media}

Level of yeast extract. In derivatives of the BS medium which did not contain any acetic acid other than that present in the trypticase, acetic acid was generally produced rather than utilized by the three Group I strains (Table 2). The relatively poor growth of strain 49 in this medium was enhanced by increasing the concentration of yeast extract to above $0.2 \%(\mathrm{w} / \mathrm{v})$, and the maximum optical density of all cultures was increased if $0.4 \%(\mathrm{w} / \mathrm{v})$ yeast extract was present. The factors in yeast extract which caused this growth stimulation have not yet been determined but of $\mathrm{I} 2$ vitamins tested, only biotin ( $40 \mu \mathrm{g} / \mathrm{IO} \mathrm{ml}$ medium) produced an increase in optical density when added to cultures grown in media containing $0.2 \%(\mathrm{w} / \mathrm{v})$ yeast extract. Whatever the level of yeast extract, the optical density of the cultures did not continue to increase once glucose had been depleted from the medium. Using high concentrations of yeast extract the amount of acetate produced by all strains was reduced.

Level of carbohydrate. When a VFA mixture was added to the medium containing a high concentration of yeast extract, the three Group I organisms NOR37, IL63 I and 49 all utilized between 17.8 and $25^{\circ} 0 \mu \mathrm{mol}$ acetate $/ 100 \mu \mathrm{mol}$ hexose. Acetate was also utilized when cellobiose or maltose were substrates (Table 2). In the presence of all three sugars the amount of acetate taken up was increased approximately in proportion to the additional carbohydrate fermented. In this case, the total amount of carbohydrate was not growth limiting. Strain $\mathrm{D}_{1}$ utilized considerably less acetate than the other strains and produced small quantities of acetate when all three sugars were present in the medium.

When glucose was the only carbohydrate present, acetate utilization by the three Group I strains was greater if the amount of glucose in the medium was growth-limiting rather 
Table I. Fermentation products of five strains of B. fibrisolvens grown in a rumen fluid cellobiose broth medium (Kistner, 1960)

\begin{tabular}{|c|c|c|c|c|c|}
\hline \multirow[b]{2}{*}{ Product } & \multicolumn{5}{|c|}{$\begin{array}{l}\text { Concentration of product } \\
(\mu \mathrm{mol} / 100 \mu \mathrm{mol} \text { hexose })\end{array}$} \\
\hline & NOR37 & IL63I & 49 & $D_{1}$ & xio \\
\hline Formic acid & $33 \cdot 7$ & $26 \cdot 7$ & $27 \cdot 3$ & $49 \cdot 0$ & $62 \cdot 3$ \\
\hline Acetic acid & $-20 \cdot 0^{*}$ & $-39 \cdot I$ & $-20 \cdot I$ & $4 \cdot 2$ & II 99 \\
\hline Propionic acid & 0.7 & 0.0 & 0.4 & 0.0 & 0.4 \\
\hline n-Butyric acid & $53 \cdot 5$ & $49 \cdot 2$ & $40 \cdot 5$ & $38 \cdot 8$ & $36 \cdot 5$ \\
\hline $\mathrm{L}(+)$-Lactic acid & $64 \cdot 4$ & $84 \cdot 2$ & 113.3 & $55 \cdot 5$ & $23 \cdot 4$ \\
\hline Ethanol & $3 \cdot 0$ & $3 \cdot 8$ & $3 \cdot 4$ & $4 \cdot 2$ & $4 \cdot 1$ \\
\hline Hydrogen & $57 \cdot 0$ & $2 \cdot 3$ & $37 \cdot 1$ & $32 \cdot 3$ & $38 \cdot I$ \\
\hline
\end{tabular}

Table 2. Changes in acetate concentration after growth in batch culture of four strains of $B$. fibrisolvens in derivatives of $B S$ medium

Concentrations of glucose, cellobiose and maltose were such that, when added separately, they gave $25 \mu \mathrm{mol}$ hexose $/ \mathrm{ml}$ medium, and when added as a mixture, they gave $12.5 \mu \mathrm{mol}$ each carbohydrate $/ \mathrm{ml}$ medium.

\begin{tabular}{|c|c|c|c|c|c|c|c|c|}
\hline \multicolumn{5}{|c|}{ Addition to BS medium } & \multicolumn{4}{|c|}{$\begin{array}{l}\text { Concentration of acetate } \\
(\mu \mathrm{mol} / \mathrm{I} 00 \mu \mathrm{mol} \text { hexose })\end{array}$} \\
\hline Glu & Cell & Mal & $\begin{array}{c}\text { YE } \\
(\%, w / v)\end{array}$ & $\begin{array}{c}\text { VFA } \\
(\%, v / v)\end{array}$ & NOR37 & IL63I & 49 & $\mathrm{D}_{1}$ \\
\hline+ & 0 & 0 & 0.1 & 0.0 & $7 \cdot 9$ & $12 \cdot I$ & $9 \cdot 3$ & $7 \cdot 2$ \\
\hline+ & 0 & 0 & 0.4 & 0.0 & 0.0 & $7 \cdot 2$ & 6.8 & 3.0 \\
\hline+ & 0 & 0 & 0.4 & 0.31 & $-22 \cdot 5^{*}$ & -25.0 & -25.0 & $-3 \cdot I$ \\
\hline 0 & + & 0 & 0.4 & 0.31 & -22.5 & -17.8 & $-22 \cdot 8$ & $-8 \cdot 2$ \\
\hline 0 & 0 & + & 0.4 & 0.31 & $21 \cdot 5$ & $-2 I \cdot 4$ & $-I 9 \cdot 6$ & $-7 \cdot 2$ \\
\hline+ & + & + & 0.4 & 0.31 & $-30 \cdot 7$ & $-29 \cdot 3$ & $-30 \cdot 7$ & $I \cdot 8$ \\
\hline
\end{tabular}

Glu, glucose; Cell, cellobiose; Mal, maltose; YE, yeast extract; VFA, volatile fatty acid solution. $o$, not added to medium.

* - , utilization.

Table 3. Changes in acetate concentration after growth in batch culture of four strains of $B$. fibrisolvens in BSA medium containing $10 \mu \mathrm{mol}$ added acetate/ml and growth-limiting and non-limiting amounts of glucose

\begin{tabular}{|c|c|c|c|c|c|}
\hline & \multirow{2}{*}{$\begin{array}{c}\text { Concentration of } \\
\text { glucose } \\
(\mu \mathrm{mol} / \mathrm{ml} \text { medium })\end{array}$} & \multicolumn{4}{|c|}{ Concentration of acetate $(\mu \mathrm{mol} / 100 \mu \mathrm{mol}$ hexose $)$} \\
\hline & & NOR37 & IL63I & 49 & $\mathbf{D}_{\mathbf{1}}$ \\
\hline Limiting & $5 \cdot 0$ & $-16 \cdot 8^{*}$ & $-17 \cdot 0$ & $-15 \cdot 2$ & $-6 \cdot 0$ \\
\hline Limiting & $10 \cdot 0$ & $-I 3 \cdot I$ & $-18 \cdot 2$ & $-19 \cdot 2$ & $3 \cdot 0$ \\
\hline Limiting & 25.0 & -15.7 & $-2 I \cdot 2$ & -19.9 & -2.9 \\
\hline & Ivich & -152 & -100 & -10.1 & ND \\
\hline Non-limiting & $45 \cdot 0$ & $-6 \cdot 8$ & $-3 \cdot 6$ & $-5 \cdot 2$ & $2 \cdot 2$ \\
\hline
\end{tabular}

than in excess (Table 3 ). In contrast to results with the mixed sugars, less acetate was utilized with a non-limiting glucose concentration $\left(45 \mu \mathrm{mol} \mathrm{ml}^{-1}\right)$. Acetate uptake or production by strain $D_{1}$ was variable at all glucose concentrations.

Effect of VFA, sodium lactate and low initial $\mathrm{pH}$. The addition of propionic or n-butyric acids to the BSA + glucose medium had little effect on acetate uptake. However, the addition 
Table 4. Changes in acetate concentration after growth in batch culture of four strains of B. fibrisolvens in BSA medium containing high or low levels of available $\mathrm{CO}_{2}$ and in the presence or absence of sodium lactate

The BSA medium contained added acetate and glucose at concentrations of 10 and $25 \mu \mathrm{mol} / \mathrm{ml}$ medium respectively. High levels of available $\mathrm{CO}_{2}$ were provided by using $\mathrm{HCO}_{3}-/ \mathrm{CO}_{2}$ buffer, $\mathrm{pH} \mathrm{6.8,} \mathrm{and} 100 \% \mathrm{CO}_{2}$ as the headspace gas; low levels were provided by using $0.2 \mathrm{M}$-phosphatecitrate buffer, $\mathrm{pH} 6 \cdot 8,0.04 \%(\mathrm{w} / \mathrm{v}) \mathrm{Na}_{2} \mathrm{CO}_{3}$ and $100 \% \mathrm{~N}_{2}$ as the headspace gas.

\begin{tabular}{|c|c|c|c|c|c|}
\hline \multirow[b]{2}{*}{ Available $\mathrm{CO}_{2}$} & \multirow{2}{*}{$\begin{array}{l}\text { Sodium lactate } \\
\qquad(\mu \mathrm{mol} / \mathrm{ml})\end{array}$} & \multicolumn{4}{|c|}{ Concentration of acetate $(\mu \mathrm{mol} / 100 \mu \mathrm{mol}$ hexose $)$} \\
\hline & & NOR37 & IL63I & 49 & $\mathrm{D}_{1}$ \\
\hline $\begin{array}{l}\text { High } \\
\text { High }\end{array}$ & $\begin{array}{c}0 \\
30 \cdot 0\end{array}$ & $\begin{array}{l}-27 \cdot 5^{*} \\
-32.5\end{array}$ & $\begin{array}{l}-17.9 \\
-19.6\end{array}$ & $\begin{array}{r}2 \cdot 5 \\
-8 \cdot 6\end{array}$ & $\begin{array}{l}3 \cdot 2 \\
1 \cdot 0\end{array}$ \\
\hline Low & 0 & $-26 \cdot 4$ & $-2 I \cdot 8$ & $-5 \cdot 0$ & 0.0 \\
\hline Low & $30 \cdot 0$ & $\begin{array}{l}-39 \cdot 0 \\
-, \text { utili }\end{array}$ & -25.7 & $-I I \cdot I$ & $-12 \cdot 9$ \\
\hline
\end{tabular}

of sodium lactate ( $30 \mu \mathrm{mol} \mathrm{ml})^{-1}$ ) caused a small but consistent stimulation of acetate uptake by NOR37 and IL63I (Table 4). Strain 49 changed from being a weak acetate producer to being an acetate consumer. Reducing the availability of $\mathrm{CO}_{2}$ also stimulated acetate utilization by strains IL63I and 49 and reduced the amount of acetate produced by $D_{1}$. When sodium lactate was incorporated into this low $\mathrm{CO}_{2}$ medium, acetate uptake by all strains was markedly stimulated compared with the control BSA + glucose medium, but the growth rate of the organisms was reduced. None of the organisms was capable of fermenting lactic acid as a sole energy source but small quantities of lactate $(<3 \mu \mathrm{mol} / 100 \mu \mathrm{mol}$ hexose $)$ were apparently taken up from the medium when NOR37 was grown in the presence of glucose, acetic acid and sodium lactate.

The terminal $\mathrm{pH}$ of cultures grown in BSA + glucose medium was rarely less than 6.6 and never below 6.4 . The effect of the initial $\mathrm{pH}$ of the medium on acetate utilization varied between strains. For example, with BSA medium containing glucose $\left(25 \mu \mathrm{mol} \mathrm{ml}^{-1}\right)$ acetate consumption by NOR37 increased by $\mathrm{I} 5 \mu \mathrm{mol} / \mathrm{I} 00 \mu \mathrm{mol}$ hexose when the initial $\mathrm{pH}$ of the medium was $6 \cdot 2$. None of the other strains grew well in media having an initial $\mathrm{pH}$ below 6.4 , but, at this $\mathrm{pH}$, strain IL63I utilized an additional $5.2 \mu \mathrm{mol}$ acetate $/ 100 \mu \mathrm{mol}$ hexose. The growth rate and maximum optical density of all cultures were reduced by growth in media of $\mathrm{pH} 6.4$ or below.

Release of fermentation acids during batch culture. In view of the variation in the extent of acetate uptake shown by individual strains, batch cultures in BSA medium containing 10 $\mu \mathrm{mol}$ acetate $/ \mathrm{ml}$ and $25 \mu \mathrm{mol}$ glucose $/ \mathrm{ml}$ were monitored for changes in the concentration of acetic, n-butyric and lactic acids throughout the growth cycle. Using this medium, the release of fermentation acids during the growth of all strains followed the same general pattern, shown in Fig. I $(a)$ for strain NOR37. During the exponential phase of growth (exponential growth rate, 1.87 generations/h), n-butyric, lactic and acetic acids accumulated rapidly. On entering the stationary phase, when the glucose had been depleted almost to zero, acetate uptake commenced while n-butyrate synthesis continued, though at a much reduced rate. Surprisingly, negative changes in net acetate concentration were not always obtained during the incubation period. An increase in the concentration of acetate added to the medium to $5 \mu \mathrm{mol} \mathrm{ml} l^{-1}$ or above gave rise to a second pattern of fermentation with strain $\mathrm{D}_{1}$ (Fig. I $b$ ) in which acetate utilization started from the onset of growth and continued throughout exponential growth. The growth rate, 0.97 generations/h, was lower than in the 


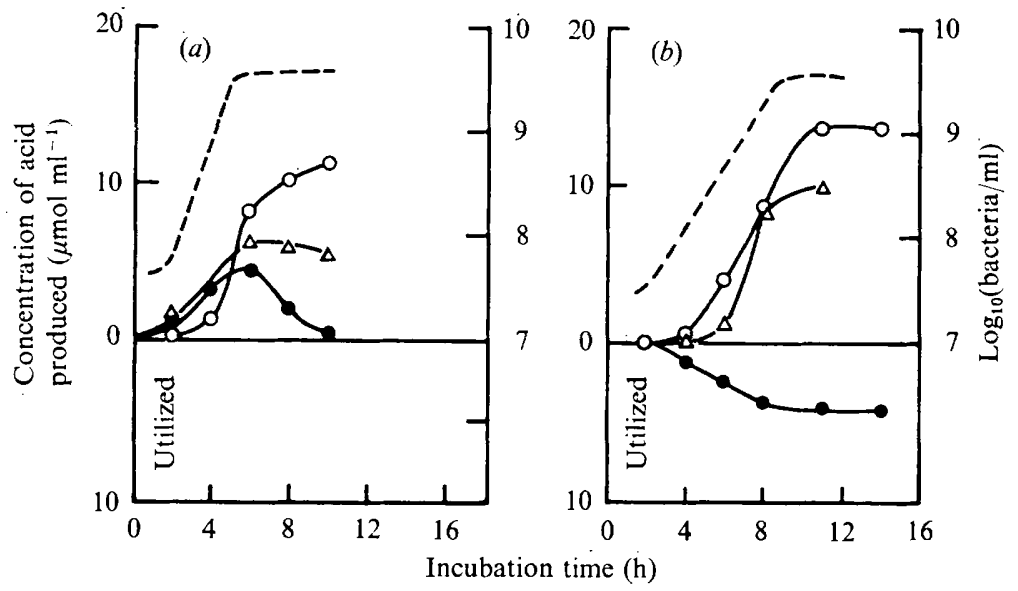

Fig. I. Growth curves and acids produced or utilized during batch growth of $\boldsymbol{B}$. fibrisolvens on BSA medium containing $25 \mu \mathrm{mol}$ glucose $/ \mathrm{ml}$ and $(a) 10 \mu \mathrm{mol}$ acetate $/ \mathrm{ml}$, strain NoR 37 , or $(b)$ I $5 \mu \mathrm{mol}$ acetate $/ \mathrm{ml}$, strain $\mathrm{D}_{1}$. $\odot$, Acetic acid; $O, \mathrm{n}$-butyric acid; $\Delta$, lactic acid. The broken line indicates the growth curve, determined by direct counts.

Table 5. Acetate uptake or production by five strains of B. fibrisolvens grown in batch culture in BSA medium containing $25 \mu \mathrm{mol}$ glucose/ml and various amounts of added acetic acid

\begin{tabular}{|c|c|c|c|c|c|}
\hline \multirow{2}{*}{$\begin{array}{c}\text { Concn of acetic } \\
\text { acid } \\
(\mu \mathrm{mol} / \mathrm{ml} \text { medium })\end{array}$} & \multicolumn{5}{|c|}{ Concentration of acetate ( $\mu \mathrm{mol} / \mathrm{I} 00 \mu \mathrm{mol}$ hexose) } \\
\hline & NOR37 & IL63I & 49 & $D_{1}$ & KIO \\
\hline 0 & $I \cdot I$ & $7 \cdot 2$ & $7 \cdot 6$ & $10 \cdot 8$ & $16 \cdot 2$ \\
\hline 5 & $-14 \cdot 4^{*}$ & $-16 \cdot 6$ & 0.7 & $10 \cdot 8$ & $20 \cdot 9$ \\
\hline IO & $-I 8 \cdot I$ & -18.0 & -4.0 & $2 \cdot 2$ & 14.8 \\
\hline 15 & $-26 \cdot 4$ & $-28 \cdot 9$ & $-20 \cdot 6$ & $-23 \cdot I$ & $18 \cdot 4$ \\
\hline 25 & $-30 \cdot 3$ & $-35 \cdot 4$ & $-19 \cdot 5$ & $-24 \cdot 9$ & $18 \cdot 4$ \\
\hline 50 & $-37 \cdot 2$ & $-30 \cdot 7$ & $-2 I \cdot 7$ & $-30 \cdot 0$ & $18 \cdot 1$ \\
\hline
\end{tabular}

previous medium. Butyrate and lactate were produced and the rate of production of butyric acid was proportional to the rate of growth. On entering the stationary phase, the organism no longer utilized acetate and stopped producing the other acids.

Influence of concentration of extracellular acetate. Since increasing the concentration of acetate in the medium caused $D_{1}$ to shift from one type of fermentation to the other, the possibility that some threshold concentration of acetate was required in order to stimulate acetate uptake was investigated. The organisms, including for comparison the Group 2 strain KIO, were grown for $48 \mathrm{~h}$ in BSA + glucose $\left(25 \mu \mathrm{mol} \mathrm{ml}^{-1}\right)$ medium with o to $50 \mu \mathrm{mol}$ acetic acid $/ \mathrm{ml}$. All strains produced acetate when grown in the absence of added acetate (Table 5) and strains NOR37 and IL63I utilized acetate from all the media containing added acetate. However, strains $D_{1}$ and 49 did not utilize acetate unless the initial concentration of acetic acid in the medium exceeded Io $\mu \mathrm{mol} \mathrm{m}^{-1}$ and $5 \mu \mathrm{mol} \mathrm{m}^{-1}$, respectively. The Group I organisms tended to utilize more acetate as its concentration was increased. The Group 2 organism, KIO, produced acetate in all media whether acetate was added or not.

Continuous-culture studies. Results from batch-culture experiments suggested that the rate of growth of butyrivibrios might have a considerable influence on the extent of acetate uptake. This was examined using strain NOR37 grown in continuous culture in BSA+glucose 


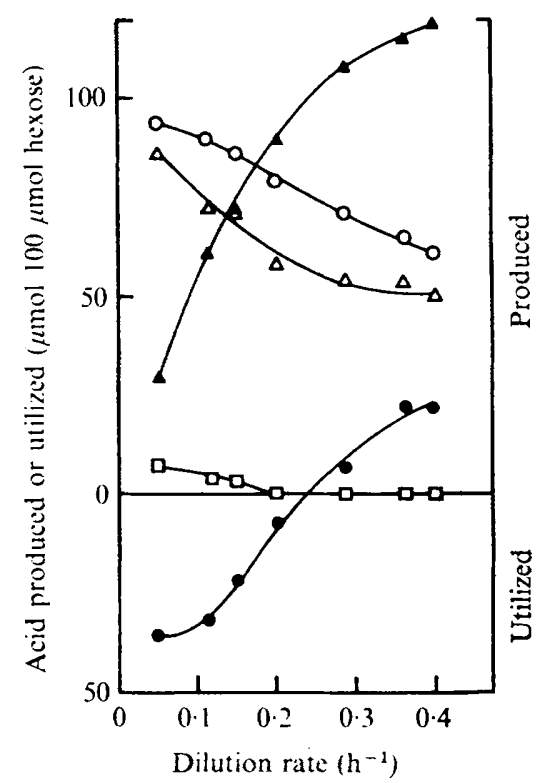

Fig. 2. Production or utilization of fermentation acids and ethanol by B. fibrisolvens strain NOR37 grown in continuous culture at different dilution rates. Medium was BSA + glucose $\left(27 \cdot 8 \mu \mathrm{mol} \mathrm{ml}^{-1}\right)$ containing acetic acid ( $5 \mu \mathrm{mol} \mathrm{ml}^{-1}$ )., Acetic acid; $O$, n-butyric acid; $\Delta$, formic acid; $\triangle$, lactic acid; $\square$, ethanol.

$\left(27 \cdot 8 \mu \mathrm{mol} \mathrm{ml}^{-1}\right)$ medium containing I $5 \mu \mathrm{mol}$ added acetate $/ \mathrm{ml}$. At low dilution rates $(D)$ of 0.05 to $0 . \mathrm{I} \mathrm{h}^{-1}$, there was considerable acetate uptake (Fig. 2). Butyric and lactic acids were the major fermentation products, with formic acid and ethanol as minor components, but as the dilution rate was increased above $0 . \mathrm{I} \mathrm{h}^{-1}$ acetate uptake decreased and the amount of formate produced increased. The production of $n$-butyric and lactic acids and ethanol all decreased as the dilution rate increased with the result that, at a dilution rate of $0.4 \mathrm{~h}^{-1}$, formic acid was the major fermentation product with butyric and lactic acids as secondary products. The organism entered a phase of relatively vigorous acetate production which reached $23 \mu \mathrm{mol} / 100 \mu \mathrm{mol}$ hexose as the dilution rate increased above $0.235 \mathrm{~h}^{-1}$. The mean carbon recovery was $105 \%$ for all samples except those taken at the lowest dilution rate where an exceptionally high, and so far unexplained, value ( $122 \%$ ) was obtained. Production of hydrogen was not measured.

\section{DISCUSSION}

When grown in a medium containing rumen fluid, three of the four strains examined, NOR37, IL63 I and 49 could be classified as Group I butyrivibrios on the basis of acetate uptake, low formate and high lactate production (Shane et al., 1969). Compared with the initial characterization of this strain (Bryant \& Small, I956), strain $D_{1}$ behaved atypically in not utilizing acetate from the rumen fluid medium. Many interrelated factors influence the uptake of acetate. Earlier work by Lee \& Moore (1959) indicated that in the presence of rumen fluid the uptake was related to the amount of rumen fluid in the medium and to the initial $\mathrm{pH}$ of the medium. The results presented here suggest that four other factors may influence acetate uptake: the level of carbohydrate; the presence of sodium lactate; the availability of $\mathrm{CO}_{2}$; and the rate of growth of the organism. For some strains, such as $\mathrm{D}_{1}$, a 
more important factor may be the concentration of extracellular acetate. Of these factors, low $\mathrm{pH}$, the presence of sodium lactate, low availability of $\mathrm{CO}_{2}$ and a high concentration of acetate (or rumen fluid) may be the factors which stimulate acetate uptake by reducing the growth rate of the organism.

This relationship between net acetate uptake and growth rate was demonstrated when strain NOR37 was grown in continuous culture under energy (glucose) limitation in a medium of constant $\mathrm{pH}$ and high availability of $\mathrm{CO}_{2}$. As the dilution rate, and hence growth rate, increased, so the amount of acetate taken up decreased, with a corresponding fall in butyrate production. Assuming that, as suggested by Joyner \& Baldwin (I966), these strains possess a coli-type phosphoroclastic system, the production of formate at all dilution rates indicates that the cleavage of pyruvate to acetate and formate proceeds even during phases of acetate uptake. The observed production or utilization of acetate may therefore be the net result of the two activities. The increasing amounts of formate synthesized at increasing growth rates suggest that the phosphoroclastic cleavage of pyruvate becomes more rapid under these conditions. If this is so, then the behaviour of an organism as a Group I or Group 2 butyrivibrio may depend in part upon the rate of this reaction.

Variations in acetate uptake or formation by strain $D_{1}$ were particularly marked. Much of the variability encountered with this strain in early experiments may have been due to the initial concentration of acetate in the medium being at, or around, a threshold value (Io to $15 \mu \mathrm{mol}$ acetate $/ \mathrm{ml}$ medium), below which acetate was a product of glucose fermentation, and above which acetate was utilized. The maximum total concentration of acetate reached in batch fermentation as the organism approached the stationary phase corresponded to this threshold value (Fig. I $a$ ).

On the basis of the batch- and continuous-culture studies with NOR37, butyrate production and acetate utilization appeared to be linked. In batch culture, when determining the acetate threshold concentration for strain $D_{1}$, the change from acetate production to utilization and the increase in butyrate production were 50 and $24 \mu \mathrm{mol} / 100 \mu \mathrm{mol}$ respectively, i.e. in the ratio $2: 1$. Similarly, using values taken from the continuous culture data, at dilution rates of $0.05 \mathrm{~h}^{-1}$ (maximum acetate uptake) and $0.235 \mathrm{~h}^{-1}$ (no net acetate uptake or production), the changes in acetate uptake and butyrate production were 36 and $\mathrm{I} 8 \mu \mathrm{mol} / \mathrm{Ioo} \mu \mathrm{mol}$ hexose, respectively. Since the normal route of butyrate synthesis involves the formation of acetoacetyl $\mathrm{CoA}$ from two moles of acetyl $\mathrm{CoA}$, it is tempting to assume that a significant proportion of the butyrate carbon synthesized during the phase of acetate uptake is derived from extracellular acetate. If extracellular acetate is used for electron disposal in this way, then to obtain any energetic advantage the organism must link the two units of reoxidized cofactors so formed to glycolysis to allow another mole of hexose to be oxidized. In those cultures in which acetate-butyrate conversions appeared to continue in the stationary phase, the necessary reducing equivalents may have arisen from the turnover of some cellular storage compound formed when glucose was still in excess. The exact fate of acetate carbon can only be determined by tracer studies. From the work of Kistner \& Kotzé (1973) it seems probable that Group I butyrivibrios are able to carry out reductive carboxylation reactions and contain a pyruvate synthetase. Randomization of some acetate carbon into lactic acid or amino acids might therefore be expected to occur.

Butyrivibrio fibrisolvens is numerically one of the most important organisms in the rumen of the roughage-fed animal. The dilution rate of the rumen fluid of such an animal is unlikely to exceed $0 \cdot I^{-1}$ and the concentration of acetate in the fluid will be at least four or five times higher than the $15 \mu \mathrm{mol} \mathrm{ml^{-1 }}$ in vitro threshold level found for strain $D_{1}$. Satter \& Esdale (1968) demonstrated that randomization of acetate carbon into butyrate was much 
greater in rumen fluid taken from animals fed with roughage than in fluid from animals fed with concentrates. It is probable that under conditions of high roughage feeding, $B$. fibrisolvens may be among the most active organisms contributing to turnover of VFA within the rumen.

N.J.L. is a visiting worker from the Department of Bacteriology, University of Athens, Greece.

The authors thank Dr M. P. Bryant and Dr N. O. van Gylswyck for supplying some of the strains, and Dr M. E. Sharpe for many valuable discussions during the course of this work. We gratefully acknowledge the excellent technical assistance of Mr G. M. Scarr.

\section{REFERENCES}

Barker, S. B. \& Summerson, W. H. (I94I). The colorimetric determination of lactic acid in biological material. Journal of Biological Chemistry 138, 533-554.

BonNichsen, R. (1965). Ethanol determination with alcohol dehydrogenase and DPN. In Methods of Enzymatic Analysis, pp. 285-289. Edited by H. U. Bergmeyer. New York: Academic.

Bryant, M. P. \& Robinson, I. M. (196I). An improved non-selective culture medium for ruminal bacteria and its use in determining diurnal variation in numbers of bacteria in the rumen. Journal of Dairy Science 44, I 446-1 456.

Bryant, M. P. \& Small, N. (1956). The anaerobic monotrichous butyric acid producing curved rod shaped bacteria of the rumen. Journal of Bacteriology 72, 16-21.

Bergey's Manual of Determinative Bacteriology, 8th edn (1974). Edited by R. E. Buchanan and N. E. Gibbons. Baltimore: Williams \& Wilkins.

Caldwell, D. R. \& Bryant, M. P. (1966). Medium without rumen fluid for non-selective enumeration and isolation of rumen bacteria. Applied Microbiology 14, 794-801.

Emmanuel, B., Milligan, L. P. \& Turner, B. V. (1974). The metabolism of acetate by rumen microorganisms. Canadian Journal of Microbiology 26, I 83-I 85.

GARVIE, E. I. (1967). The production of $L(+)$ and $D(-)$ lactic acid in cultures of some lactic acid bacteria, with special study of Lactobacillus acidophilus NCDO2. Journal of Dairy Research 34, 3I-38.

JoYNER, A. E. \& BALDWIN, R. L. (1966). Enzymatic studies of pure cultures of rumen micro-organisms. Journal of Bacteriology $92, \mathrm{I} 32 \mathrm{I}-1330$.

KistNer, A. (1960). An improved method for viable counts of bacteria of the ovine rumen which ferment carbohydrates. Journal of General Microbiology 23, 565-576.

KISTNER, A. \& Kotzé, J. P. (1973). Enzymes of intermediary metabolism of Butyrivibrio fibrisolvens and Ruminococcus albus grown under glucose limitation. Canadian Journal of Microbiology 19, I I $19-$ I I 27.

Latham, M. J., Sutton, J. D. \& Sharpe, M. E. (1974). Fermentation and micro-organisms in the rumen and the content of fat in the milk of cows given low roughage rations. Journal of Dairy Science 57, 803-810.

LEE, H. C. \& MOORE, W. E. C. (1959). Isolation and fermentation characteristics of strains of Butyrivibrio from ruminal ingesta. Journal of Bacteriology 77, 741-748.

Leng, R. A. (1970). Physiology of Digestion and Metabolism in the Ruminant, pp. 406-421. Edited by A. T. Phillipson. Newcastle upon Tyne: Oriel Press.

Rabinowitz, J. C. \& Pricer, W. E. (1965). Formate. In Methods of Enzymatic Analysis, pp. 308-312. Edited by H. U. Bergmeyer. New York: Academic.

SATTER, L. D. \& ESDALE, W. J. (1968). In vitro lactate metabolism by ruminal ingesta. Applied Microbiology I6, 680-688.

Shane, B. S., Gouws, L. \& Kistner, A. (I969). Cellulolytic bacteria occurring in the rumen of sheep conditioned to low-protein teff hay. Journal of General Microbiology 55, 445-457.

Sharpe, M. E. \& ReITER, B. (1972). Common antigenic determinant in a rumen organism and in Salmonellae containing the antigen 04 . Applied Microbiology 24, 61 3-6I7. 